\title{
A VIOLÊNCIA VIVIDA NA FAMÍLIA E NA ESCOLA: VOZES DA MEMÓRIA A SERVIÇO DA FORMAÇÃO E ATUAÇÃO DOCENTE
}

\author{
Adriele Gonçalves da Silva * \\ Marilda da Silva ${ }^{* *}$
}

\section{INTRODUÇÃO}

A origem desta pesquisa são registros de histórias de escolarização produzidos desde o ano de 2003 no âmbito da Disciplina Didática II $^{1}$ por alunos que cursam a Pedagogia na Faculdade de Ciências e Letras - Campus de Araraquara da Universidade Estadual Paulista Júlio de Mesquita Filho (UNESP). Em tal curso os estudantes rememoram a experiência escolar que vivenciaram até ingressarem na referida instituição com o objetivo de criar uma base empírica coletiva sobre as práticas pedagógicas/didáticas as quais foram submetidos ao longo da sua formação básica. Com tais informações abre-se reflexões sobre a atuação docente propriamente dita. Aproveitando, assim, o aprendizado didático que todos que frequentam a escola, conscientemente, ou não, adquirem ao longo da formação escolar de modo geral. Especificamente, esses registros ao longo de treze anos evidenciaram recorrentemente a prática de violência por professores contra alunos, desde a Educação Infantil até o Ensino Médio. Foram exatamente essas informações que inspiraram esta pesquisa.

Levando em conta a complexidade da produção da violência na sociedade e no interior das escolas faz-se necessário realizar investimentos de diferentes naturezas que provoquem ou resultem em explicações que possam ser usadas para se compreender objetivamente a composição, neste caso, do fenômeno violência em espaço escolar, tendo em vista encontrar saídas para a sua erradicação. É com este espírito que esta pesquisa foi produzida. A

\footnotetext{
* Instituto de Biociências de Rio Claro da Universidade Estadual Paulista "Júlio de Mesquita Filho", UNESP. adrielegons@gmail.com.

** Faculdade de Ciências e Letras de Araraquara e Instituto de Biociências de Rio Claro da Universidade Estadual Paulista “Júlio de Mesquita Filho”, UNESP. marilda@fclar.unesp.br.

${ }^{1}$ Esta Disciplina é ministrada pela Professora Doutora Marilda da Silva.
} 
propósito, as categorias que auxiliam a investigar e entender o fenômeno violência em espaço escolar utilizadas neste estudo são: violência na escola, violência a escola e violência da escola, por Bernard Charlot $(2002,2005)$. Assim, a "violência na escola" é entendida pelo autor como uma violência que acontece "dentro da escola" mas que não está diretamente relacionada à natureza e às práticas da instituição na qual a violência ocorreu. Sob este aspecto, a violência não tem, necessariamente, origem no espaço escolar, mas pode ter fora dele como, por exemplo, a invasão de pessoas estranhas à escola para acertos de contas cuja origem está além dos muros escolares. Por outro lado, a "violência na escola" também pode estar relacionada às atividades da escola, por exemplo, as ameaças para que o colega deixe colar na prova (CHARLOT, 2005).

Já a "violência à escola" é dirigida à escola e aos agentes que a representam: professores, coordenadores, diretores e demais funcionários. Essa violência é perpetrada por alunos por meio da destruição do patrimônio escolar e de atos de violência contra o professor e demais funcionários. Ela acontece, por exemplo, "quando os alunos provocam incêndios, batem nos professores ou os insulta" (CHARLOT 2002, p. 434). Ao lado da "violência à escola" está a "violência da escola", cometida pela escola contra os alunos por ela como instituição e pelos seus agentes. Segundo o autor trata-se de uma violência simbólica e/ou institucional que ocorre de modos variados: composição das classes, de atribuição de notas, de orientação, palavras desdenhosas dos adultos, atos considerados pelos alunos como injustos ou racistas e etc. Portanto, nesta categoria, a violência é produzida pela própria escola e por aqueles que a representam e se manifesta "sob várias formas, desde a bofetada até a chamada violência simbólica" (CHARLOT, 2005).

No que se refere à violência da escola, que é a categoria básica desta análise, dissertações e teses brasileiras sobre a violência em espaço escolar produzidas no período de 2008-2012 mostram de modo geral que a "violência da escola" remete a práticas de autoritarismo ou à relação de dominação da escola para com os alunos, objetivada por meio da aplicação de normas institucionais ou pelo modo como o corpo docente e funcionários se relacionam com os alunos. Nesse sentido, Prioto (2008, p. 66) revela que a "violência da escola" é manifestada pela "manutenção de uma postura 
autoritária de professores, de diretores e de supervisão da prática escolar diária". Segundo Costa (2011, p. 38), essa violência "materializa-se por meio dos mitos, ritos, símbolos, imagens e práticas sociais que discriminam, humilham, controlam, obrigam e excluem" os alunos. Elias (2009) acrescenta que a "violência da escola" perpassa todas as outras e pode assumir várias configurações, sejam elas implícitas ou explícitas. Trata-se, portanto, da violência produzida pela escola que se manifesta, sobretudo, pela violência simbólica. Conforme as pesquisas, a violência simbólica está na base das relações de poder no espaço escolar e dissimula o reconhecimento da realidade objetiva. A violência simbólica "é aceita, incorporada e reproduzida pelas pessoas, sem, na maioria das vezes, a percepção da sua existência" (COSTA, 2011, p. 216). Ela é, pois, este poder invisível que faz com que os agentes escolares a vejam como natural em suas relações sociais no espaço escolar e não só (BOURDIEU, 2010a, 2010b).

Tais pesquisas, ainda, evidenciaram que a "violência da escola" reflete as relações sociais tensas e conflituosas entre adultos da escola e os alunos, que são crianças e adolescentes. Os professores foram identificados como os principais perpetradores da "violência da escola" e cometem, especialmente, violências do tipo não físicas: verbal e simbólica. As formas de violência por professores, nas pesquisas, dizem respeito, sobretudo, a práticas de autoritarismo e de discriminação social. Essas violências ocorrem no ambiente da sala de aula em meio a uma relação professor-aluno baseada no exercício de práticas autoritárias que excedem o poder legítimo delegado ao professor.

Os motivos para a violência por professores estão relacionados por um lado ao disciplinamento e controle dos alunos dentro da sala de aula e por outro a preconceitos por parte dos professores em relação à realidade social, étnica, cultural e econômica dos alunos, bem como às dificuldades escolares dos mesmos. Neste contexto a "violência da escola" pode ser, em determinados casos, um desdobramento da "violência à escola" e da "violência na escola", ou seja, uma violência pode culminar em outra e, assim, o agredido se torna o agressor e vice e versa. Conclui-se com as pesquisas que as manifestações de "violência na escola", "violência à escola" e "violência da escola" se retroalimentam, culminando em um ciclo da violência em espaço 
escolar o que, consequentemente, contribui para a naturalização do fenômeno em nossa sociedade. Nesse sentido, a violência constitui-se como um fenômeno regular no cotidiano escolar, atinge todos os agentes escolares e é produzida e reproduzida dentro da escola e pela própria escola. Nesta conjuntura, dar voz aos professores sobre suas experiências com violência na infância e adolescência torna-se essencial para se produzir uma reflexão sobre a produção do fenômeno da violência em espaço escolar e especificamente sobre a "violência da escola", sem que seja uma procura de vítimas e algozes. Assim é que o objetivo desta pesquisa é: verificar se professores que atuam no Ensino Fundamental Ciclos I e II sofreram violência na família e na escola quando crianças e adolescentes e quais são suas percepções sobre a violência sofrida (caso seja essa a situação desses sujeitos) e quais relações estabelecem com a docência que exercem atualmente.

\section{METODOLOGIA}

Trata-se de uma pesquisa exploratória de abordagem qualitativa ${ }^{2}$. Fontes: sete entrevistas, semiestruturadas, realizadas com três professoras e quatro professores, que atuam no Ensino Fundamental Ciclos I e II, em uma escola pública estadual (localizada em Araraquara/SP). Especificamente, os sujeitos são: dois professores alfabetizadores (um homem e uma mulher), uma professora de Língua Portuguesa e Língua Inglesa, um professor de Geografia, um de Educação Física, um de Matemática e Ciências e uma professora de História, Filosofia e Sociologia. A maioria dos sujeitos já possui um tempo considerável de exercício docente e são professores efetivos em seus cargos, apenas dois são ainda professores iniciantes. As faixas etárias são: a) dos 20 anos: dois homens, 23 e 27, b) dos 30 anos: duas mulheres, 31 e 35, c) dos 40 : um homem, 49 e d) dos 50: um homem e uma mulher, 54, 55. As entrevistas foram realizadas com recursos da história oral (THOMPSON,1992). Isso foi feito porque, segundo o autor, entrevistas sobre a história de vida - que abarca o uso da memória e da percepção sobre a vida individual e coletiva -, pode

\footnotetext{
${ }^{2}$ Esta pesquisa foi realizada no âmbito da dissertação intitulada "Percepções de professoras e professores sobre a violência que viveram na família e na escola: analisando a violência da escola" de autoria de Silva (2015).
} 
trazer informações socialmente mais conscientes porque são mais democráticas, uma vez que esse instrumento de coleta pode permitir que o sujeito recrie uma diversidade de pontos de vista sobre o vivido, neste caso, sobre a experiência com violência na infância e adolescência produzida na família e na escola. A organização dos dados foi realizada por meio de uma inflexão à técnica Análise de Conteúdo (BARDIN, 1977). Trabalhou-se "com mensagens" explícitas sobre a experiência com violência à qual vem se referindo. E a análise propriamente dita foi operada pela fundamentação, produzindo a triangulação dos dados. No que se refere à fundamentação os autores estruturais foram: Andréa Buoro et al (1999), Bernard Charlot (2002, 2005,), José Vicente Tavares dos Santos (2009), Nancy Cardia (2012), Paulo Neves (2010), Pierre Bourdieu (2010a, 2010b), Yves Michaud (1989) e diferentes autores de teses e dissertações produzidas de 2008 a 2012 no Brasil.

\section{RESULTADOS}

Os dados mostram que os sujeitos fazem parte de contextos familiares e escolares muito diferentes entre si. Contudo, os relatos evidenciam que a violência vivida no espaço escolar e familiar tem significativas semelhanças em conformidade com a faixa etária do sujeito. Identificamos que todos os sujeitos sofreram violência na família, sobretudo na infância. As violências sofridas foram: verbal, física, verbal/física e simbólica. Os pais foram os principais agressores e as violências sofridas dizem respeito, sobretudo, a punições corporais. Os principais motivos da violência na infância são: "aprontar" ou "fazer arte". Vale dizer que o "aprontar e o fazer arte" eram situações absolutamente próprias da infância e os sujeitos as reconhecem desta forma, ao se referirem a estas situações "como coisas de crianças". A esse respeito os sujeitos também deixaram claro que tal violência estabelecia relação com a posição social que a criança ocupava à época. E afirmavam: "naquela época era assim".

Essa constatação histórica parecia recobrir a violência sofrida com o manto da naturalização. Assim é que uma professora e um professor percebem a violência sofrida na infância como um recurso educativo eficaz. Apenas uma 
professora continua considerando, na vida adulta, determinados expedientes de caráter agressivos como recursos educativos eficazes e muitas vezes necessários, sugerindo a possibilidade de reprodução dos mesmos no espaço escolar. Os demais sujeitos - três professores e duas professoras -, percebem ou reconhecem expedientes de caráter agressivos como sendo uma violência. Dois dos três professores são explicitamente contra a reprodução de qualquer tipo de violência contra criança. Já as outras duas professoras e um professor não se colocaram a esse respeito.

Além do mais, os dados mostram que a violência no espaço familiar diminuiu, visivelmente, à medida que a criança foi crescendo. Portanto, a adolescência chega e a violência cessa. No entanto, quando a violência ocorre na adolescência a violência física dá lugar à violência verbal/simbólica e à briga entre irmãos. A briga entre irmãos, por sua vez, também se constitui como um motivo para os pais cometerem violência contra os filhos que lançam mão de expedientes violentos para amenizar o ocorrido violento. As situações apresentadas pelos sujeitos a esse respeito, em certa medida, levam a pensar que muitas vezes a briga entre irmãos é uma reprodução da violência ocorrida na família como um todo. Ainda sobre os motivos e situações apontados pelos sujeitos que levaram os mesmos a sofrerem violência há dois casos diretamente ligados à adicção alcoólica por parte do pai e um caso relacionado à violência doméstica contra a mulher, a mãe.

Em relação à violência sofrida no espaço escolar seis sujeitos dos sete a sofreram, apenas uma professora não sofreu. Também na escola os sujeitos sofreram mais violência na infância do que na adolescência. Quanto aos tipos de "violência da escola" cometida por professor contra o aluno eles são: verbais, física, verbal/física e na natureza simbólica. Quando são adolescentes, sofreram mais a violência verbal e na forma simbólica. $\mathrm{Na}$ circunstância de violência simbólica os dados denunciam que o professor torna-se um estimulador na medida em que seus atos levam seus alunos a percebê-los como naturais nas relações sociais mediadas por poder. Em tais circunstâncias a violência por professor contra aluno pode figurar como um expediente "pedagógico" quando se trata de relações sociais, quer seja na escola, quer seja fora dela. Segundo Santos (2009, p. 13) "sempre uma violência é antecedida, ou justificada, prévia ou posteriormente, por uma 
violência simbólica, que se exerce mediante uma subjetivação pelos agentes sociais envolvidos na relação". Como bem demonstra Bourdieu (2010a, 2010b), a violência simbólica é este poder invisível exercido através da cumplicidade dos que estão sujeitos a ela e dos que a exercem. Sendo assim, muitas manifestações da violência no espaço escolar não são percebidas como tal, como é o caso dos atos violentos perpetrados por professores contra alunos.

No que se refere à faixa etária dos sujeitos os três sujeitos que estão na faixa dos 40 e dos 50 anos são aqueles que sofreram intensamente a "violência da escola", física e simbólica. Vale destacar que no período em que estudaram a punição física ainda era uma prática amplamente aceita na educação escolar como um recurso educativo. No grupo mencionado a "violência da escola" figurou, sobretudo, como práticas de autoritarismo e discriminação social. Já nos demais grupos etários a "violência da escola" ganha outra configuração. Ela é manifestada pela violência verbal e simbólica e ocorre, muitas vezes, em consonância à "violência à escola". Reitera-se que as pesquisas analisadas de 2008-2012 apontam que a "violência da escola" cometida por professores contra alunos em sala de aula versa, sobretudo, sobre práticas de autoritarismo e discriminação social. Veja que tais pesquisas são referentes a contextos escolares atuais e as entrevistas com as professoras e professores correspondem ao tempo passado, e ainda assim, apresentam dados semelhantes quanto a violência em espaço escolar.

Ademais, os professores que entrevistamos relatam que a "violência da escola" que sofreram por seus professores era motivada por situações em que apresentavam dificuldades de aprendizagem de algum conteúdo curricular e se dá na relação estabelecida entre o professor e aluno, durante o processo ensino-aprendizagem o que as pesquisas analisadas também revelam sobre a violência por professores (SILVA, 2015) e que temos, igualmente, mostrado em nossas pesquisas (SILVA, A. G., 2011; SILVA, M. da., 2013a; SILVA, M. da. et al., 2013b, 2012, 2011a, 2011b, 2011c, 2011d, 2011e, 2010a, 2010b, 2009a, $2009 b, 2009 c)^{3}$. Neste sentido, vale dizer que embora a violência no espaço

\footnotetext{
${ }^{3}$ Estudos desenvolvidos pelo "Grupo de estudo e pesquisa sobre Educação escolarizada a partir das ideias de Pierre Bourdieu" credenciado no Conselho Nacional de Desenvolvimento Científico e Tecnológico - CNPq.
} 
escolar tenha mudado de forma com o passar do tempo e com as mudanças sociais e culturais, ganhando outras dimensões e contornos, seu sentido ainda parece ser o mesmo uma vez que professores também vivenciaram a mesma violência quando ocupavam a posição de aluno. Esses dados sugerem, assim, a possibilidade da produção do ciclo da violência em espaço escolar, bem como de uma cultura da violência que tem transpassado gerações.

Vale evidenciar que as três professoras e os quatro professores construíram suas percepções sobre a violência a partir de suas vivências com a mesma, neste caso, com a violência que sofreram na família e na escola durante a infância e adolescência. Neste sentido, o efeito dessa exposição à violência para e na realização do trabalho docente que se efetivam e especificamente para e na relação que os professores estabelecem com seus alunos (crianças e adolescentes) pode correr o risco de cair na reprodução do vivido. Isto está sendo dito por que a violência que nossos sujeitos sofreram de seus pais e responsáveis possuía, na maioria dos casos, um viés educativo. Esse dado torna a possibilidade da reprodução da violência no exercício docente ainda mais provável, considerando a aprendizagem social da violência (CARDIA, 2012). Todavia, nossa pesquisa constata a possibilidade de crítica do vivido na constituição da percepção dos sujeitos sobre violência, bem como o reconhecimento dos mesmos quanto à reprovação social e até mesmo legal das práticas violentas a que foram expostos. Assim, práticas violentas consideradas por uma geração como naturais para outra pode não ser ${ }^{4}$. Por fim, nas entrevistas, vimos que práticas violentas no âmbito familiar e escolar se assemelham em muitos aspectos, especificamente, quando funcionam sob a égide da prerrogativa educativa.

\section{CONCLUSÕES}

No que se refere à violência em espaço escolar e à violência da escola - esta última na modalidade violência de professores contra alunos -,

\footnotetext{
${ }^{4}$ Contudo, nossa pesquisa não observou os sujeitos em sala de aula e na relação com seus alunos. $\mathrm{E}$ isso pode ser um viés negativo para os resultados desta pesquisa. Todavia, nossa trajetória de investigação sobre violência por professores contra alunos já mostrou suficientemente o quanto é difícil fazer uma pesquisa in lócus para obter dados sobre essa questão.
} 
busca-se amparo em Charlot (2002): a violência em espaço escolar tende a ser percebida na atualidade como um fenômeno novo, contudo, não o é. O que tem de novo são as formas assumidas na sua constituição e o modo como a percebemos. Os dados evidenciaram que a violência da escola (como da família) esteve presente na história de escolarização de todos os professores(as) entrevistados, mais na infância, menos na adolescência. Visando a força histórica do fenômeno em questão a "violência da escola" precisa ocupar na formação e atuação docente lugar privilegiado de reflexão, para que essa "história educativa" tenha um fim.

\section{REFERÊNCIAS}

BOURDIEU, Pierre. A dominação masculina. 9. ed. Rio de Janeiro: Bertrand Brasil, 2010a.

O poder simbólico. 14. ed. Rio de Janeiro: Bertrand Brasil, $2010 \mathrm{~b}$. BUORO, Andréa. et al. Violência urbana: dilemas e desafios. 3. ed. São Paulo: Atual, 1999.

CARDIA, Nancy (Coord.). Pesquisa nacional, por amostragem domiciliar, sobre atitudes, normas culturais e valores em relação à violação de direitos humanos e violência: Um estudo em 11 capitais de estado. São Paulo: Núcleo de Estudos da Violência da Universidade de São Paulo, 2012. Disponível em: < http://www.nevusp.org/downloads/down264.pdf > . Acesso em 20 de fev. 2016.

CHARLOT, Bernard. Prefácio. In: ABRAMOVAY, Miriam. Cotidiano das escolas: entre violências. Brasília: UNESCO, Observatório de Violência, Ministério da Educação, 2005.

Violência na escola: como os sociólogos franceses abordam essa questão. Sociologias, Porto Alegre, n.8, p.432-443, jul./dez. 2002. Disponível em:<http://www.scielo.br/scielo.php?script=sci_arttext\&pid=\$151745222002000 200016\&lng=pt\&nrm=iso >. Acesso em: 20 de fev. 2016.

COSTA, Jaqueline Batista de Oliveira. Adolescência e Violência escolar: das representações sociais às propostas de prevenção. 2011. $331 \mathrm{f}$. Tese (Doutorado em Educação), Pontifícia Universidade Católica de São Paulo, São Paulo, 2011.

ELIAS, Maria Auxiliadora. Violência escolar e implicações para o currículo: o projeto pela vida, não à violência - tramas e traumas. 2009. 294 f. Tese (Doutorado em Educação), Pontifícia Universidade Católica de São Paulo, São Paulo, 2009.

MICHAUD, Yves. A violência. São Paulo: Ática, 1989. 
NEVES, Paulo. Violência e cotidiano escolar: um dilema societário. In: HENNING, Leoni Maria Padilha; ABUUD, Maria Luiza Macedo (Org.). Violência, indisciplina e educação. Londrina: Eduel, 2010.

PRIOTTO, Elis Palma. Violência escolar: políticas públicas e práticas educativas. 2008. 200 f. Dissertação (Mestrado em Educação), Pontifícia Universidade Católica do Paraná, Curitiba, 2008.

SANTOS, José Vicente Tavares dos. Violências e Conflitualidades. Porto Alegre: Tomo Editorial, 2009.

SILVA, Adriele Gonçalves da. Percepções de professoras e professores sobre a violência que viveram na família e na escola: analisando a violência da escola. 2015. 183 f. Dissertação (Mestrado) - Curso de Educação, Universidade Estadual Paulista, Instituto de Biociências de Rio Claro, Rio Claro, 2015.

. Violência por professores e professoras na voz de suas vítimas: uma estrutura do habitus profissional em professores brasileiro. São Paulo: FAPESP, 2011.

; SILVA, Marilda da. Relatos de violência praticada por professores brasileiros contra seus alunos em sala de aula. In: 9aㅡ JORNADA CIENTÍFICA E TECNOLÓGICA DA UFSCAR, 9., 2011, São Carlos. Anais... São Carlos: UFSCar, 2011a.

- Violência cometida por professores brasileiros contra seus alunos em sala de aula. In: 19 SIMPÓSIO INTERNACIONAL DE INICIAÇÃO CIENTÍFICA DA USP - SIICUSP, 19, 2011, São Paulo. Anais... São Paulo: USP, 2011b.

Violência por professores e professoras na voz de suas vítimas: uma estrutura do habitus profissional em professores brasileiros. In: XXIII CONGRESSO DE INICIAÇÃO CIENTÍFICA DA UNESP, 23, 2011, Águas de São Pedro. Anais... São Paulo: UNESP, 2011c.

SILVA, Marilda da. A violência da escola na voz de futuros professores: uma probabilidade da produção da cultura da violência em ambientes escolares?. Educar em Revista, Curitiba, n. 49, p.339-353, jul. 2013. Disponível em: <http://www.scielo.br/pdf/er/n49/a19n49.pdf>>. Acesso em: 05 out. 2014.

; SILVA, Adriele Gonçalves da. Violência por professores contra alunos: uma face do fenômeno violência em meio escolar. In: XI CONGRESSO NACIONAL DE EDUCAÇÃO, II SEMINÁRIO INTERNACIONAL DE REPRESENTAÇÕES SOCIAIS, SUBJETIVIDADES E EDUCAÇÃO E IV SEMINÁRIO INTERNACIONAL SOBRE PROFISSIONALIZAÇẨO DOCENTE SPID/CÁTEDRA UNESCO, 2013, Curitiba. Anais... Curitiba: Champagnat Editora, 2013. p. 28674 - 28686. 
; CARLINDO, Eva Poliana. A história de escolarização como fonte de conteúdos para formação docente: a evidência de violência em meio escolar por professores brasileiros. In: $8^{\circ}$ CONGRESSO INTERNACIONAL DE EDUCACIÓN SUPERIOR: LA UNIVERSIDAD POR EL DESAROLLO SOSTENIBLE, 8., 2012, Havana. Anais... Anais... Havana: Distribuidora Nacional Icaic, 2012. p. $2340-2348$.

; . Atos agressivos físicos e verbais cometidos por professores contra seus alunos: um estudo a partir de histórias de escolarização. In: $X$ CONGRESSO NACIONAL DE EDUCAÇÃO E I SEMINÁRIO INTERNACIONAL DE REPRESENTAÇÕES SOCIAIS, SUBJETIVIDADES E EDUCAÇÃO, 2011, Curitiba. Anais... Curitiba: Champagnat Editora, 2011, p. 1830 -1844.

. Violência por professores em sala de aula: informações indispensáveis a processos formativos para a educação básica. In: X CONGRESSO ESTADUAL PAULISTA SOBRE FORMAÇÃO DE EDUCADORES - FORMAÇÃO DE PROFESSORES E A PRÁTICA DOCENTE: OS DILEMAS CONTEMPỐRANEOS, 5., 2009, Águas de Lindóia. Anais... São Paulo: Tec Art Editora Ltda, 2009, p. 9578-9591.

; SCARLATTO, Elaine Cristina. Violência em meio escolar no Brasil: uma alternativa formativa para professores e futuros professores. Revista Ibero-americana de Estudos em Educação, Araraquara, v. 4, n. 3, p.1-17, jan. 2009. Disponível em:<http://seer.fclar.unesp.br/iberoamericana/article/view/2764>. Acesso em: 27 fev. 2015.

A violência cometida por professores/as em escolas brasileiras: uma face da cartografia brasileira. In: XI CONGRESSO LUSOAFRO-BRASILEIRO DE CIÊNCIAS SOCIAIS: DIVERSIDADE E DESIGUALDADES, 6., 2011, Salvador. Anais... Salvador: UFBA, 2011. p. 113. Disponível em:

<http://www.xiconlab.eventos.dype.com.br/resources/anais/3/1307141352_AR QUIVO_SALVADOR_2011.pdf>. Acesso em: 25 fev. 2015.

; CARLINDO, Eva Poliana; SCARLATTO, Elaine Cristina. Violências por professores/as contra seus/as alunos/as. Revista LEVS, Marília, v. 06, p. 90101, 2010a.

Violências por professores/as contra seus/as alunos/as: primeiras reflexões. In: VI SEMINÁRIO DE DIREITOS HUMANOS DO SÉCULO XXI \& IV ENCONTRO DE DIREITOS HUMANOS DA UNESP, 2010, Marília. Anais... Marília: Oficina Universitária, 2010b, p. 1-12.

; DINIZ, Julia Elaine; SILVA, Adriele Gonçalves da. Alunos sofrem violência para aprender: uma face da exclusão escolar e social. In: 12 ${ }^{\underline{a}}$ CONFERÊNCIA INTERNACIONAL SOBRE REPRESENTAÇÕES SOCIAIS: DESAFIOS DA CONTEMPORANEIDADE E IV COLÓQUIO LUSOBRASILEIRO SOBRE SAÚDE, EDUCAÇÃO E REPRESENTAÇÕES SOCIAIS, 2014, São Paulo. Anais... São Paulo, 2011. P. 3029-3037. 